University of Windsor

Scholarship at UWindsor

$10-2010$

\title{
When hospitals provide HR practices tailored to older nurses, will older nurses stay? It may depend on their supervisor
}

Francine K. Schlosser

Odette School of Business, University of Windsor

Marjorie Armstrong-Stassen

Follow this and additional works at: https://scholar.uwindsor.ca/odettepub

Part of the Business Commons

\section{Recommended Citation}

Schlosser, Francine K. and Armstrong-Stassen, Marjorie. (2010). When hospitals provide HR practices tailored to older nurses, will older nurses stay? It may depend on their supervisor. Human Resource Management Journal, 20 (4), 375-390.

https://scholar.uwindsor.ca/odettepub/121

This Article is brought to you for free and open access by the Odette School of Business at Scholarship at UWindsor. It has been accepted for inclusion in Odette School of Business Publications by an authorized administrator of Scholarship at UWindsor. For more information, please contact scholarship@uwindsor.ca. 
When hospitals provide HR practices tailored to older nurses, will older nurses stay? It may depend on their supervisor.

Armstrong-Stassen, M. and Schlosser, F.K., When hospitals provide HR practices tailored to older nurses, will older nurses stay? It may depend on their supervisor., Human Resource Management Journal, 20(4), 375-390, 2010, November. 


\begin{abstract}
This longitudinal study tested a model of the mechanisms through which HR practices are linked to older nurses' intention to remain with their hospital. The participants were 528 registered nurses aged 45 to 67 years. The study focused on two HR practices, flexible work options and performance evaluation practices, which are more directly under the influence of the immediate supervisor. Supervisor-related procedural justice mediated the relationship between the HR practices and perceived supervisor support (PSS) and, in turn, PSS was associated with enhanced perceived organisational support (POS). POS partially mediated the relationship between PSS and affective commitment and affective commitment fully mediated the relationship between POS and older nurses' intention to remain with their hospital. The findings indicate that fostering older nurses' commitment and ultimately retention requires HR practices relevant to older nurses, supportive and fair supervisors, and a hospital that values their contribution and cares about their well-being.
\end{abstract}




\section{INTRODUCTION}

The global shortage of nurses represents a major human resource management challenge for healthcare systems in many countries (Buchan and Calman, 2004). Nurses make up the largest body of healthcare providers in most health systems and thus a shortage of nurses seriously jeopardizes the overall quality of patient care and the wellbeing of a country's population in general (International Council of Nurses, 2006). A key driving force of the nursing shortage is the ageing of the nursing workforce worldwide (Spetz, 2005). At the same time, many developed countries are facing what Buchan and Calman (2004:20) termed "a demographic double whammy" - an ageing nursing workforce and greater demands being placed on healthcare services by an ageing population. These demographic shifts in the general population as well as in the nurse population indicate that the current nursing shortage is unlikely to be reversed in the near future and in fact the shortage is projected to increase over the next two decades (Spetz, 2005).

One possible solution to the nursing shortage is for employers to retain older nurses (Hatcher et al., 2006; Simoens et al., 2005). Employers will not only benefit from the experience and expertise of older nurses but also because of declining enrolments of younger people in nursing programs the retention of older nurses is one of the most practical solutions to the nursing shortage. This will require employers to be sensitive to the needs of older nurses and, more specifically, to implement HR practices that accommodate older nurses' needs and preferences (Goodin, 2003; Hatcher et al., 2006). However, the evidence suggests that most employers are not only ill-prepared to deal with an ageing nursing workforce but also most employers have made little attempt to 
implement strategies that explicitly focus on the needs of older nurses (ArmstrongStassen, 2005).

A myriad of recommended HR practices that hospitals should implement to retain older nurses abounds in the nursing literature (e.g., Blakeley and Ribeiro, 2008; Buchan, 1999; Cohen, 2006; Spetz, 2005). However, there is a lack of empirical evidence that these HR practices do indeed influence the retention of older nurses (Armstrong-Stassen, 2005; Hatcher et al., 2006) and even less attention has been paid to the potential mechanisms through which these HR practices may operate. Given that HR practices may have relatively distal rather than immediate influences on the decision of individuals to remain with their organisation (Allen et al., 2003), the purpose of the present study was to develop and test a model of the mechanisms through which HR practices are linked to

older nurses' intention to remain with their hospital. Although some of the proposed relationships have been well documented in the research literature, such as those between perceived organisational support, affective organisational commitment, and turnover intentions, these relationships have not been examined in the context of older nurses. In addition, the study focused on those HR practices that are more directly under supervisor influence and the role played by the supervisor's enactment of these practices.

\section{Conceptual model}

We drew on social exchange theory to develop the conceptual model for this study (see Figure 1). According to social exchange theory (Blau, 1964), positive, beneficial actions directed at employees by either the organisation and/or its representatives (e.g., supervisors) contribute to the establishment of high-quality exchange relationships that create obligations for employees to reciprocate in positive, 
beneficial ways (Settoon et al., 1996). Social exchange theory has been considered a cornerstone for research on support and commitment (Bishop et al, 2005). Moreover, supervisors have been found to be critical agents in social exchange processes (GouldWilliams and Davies, 2005). We proposed that perceptions of supervisor-related procedural justice, perceptions of supervisor support (PSS) and organization support (POS), and affective organisational commitment are exchange mechanisms that mediate the relationship between perceptions of HR practices and intention to remain with the organisation. Specifically, the relationship between older nurses' perceptions of HR practices and their intentions to remain with their hospital is mediated by their perception of how fairly their immediate supervisor administers HR practices over which the supervisor has direct control, how supportive they perceive their immediate supervisor to be, how supportive they perceive their hospital to be, and their affective commitment to their hospital.

put figure one here

HR practices provide employees with concrete and visual evidence of the organisation's intent to anticipate and meet their needs. When an organisation engages in HR practices that reflect investment in and support of its employees, it signals that the organisation is seeking to continue a social exchange relationship with its employees (Allen et al., 2003). Social exchange relationships are found between workers and their supervisors as well as between workers and their organisation (Rupp and Cropanzano, 2002; Wayne et al., 1997). Research has shown that supervisors play an important role in developing employees' perceptions of the organisation (Wayne et al., 1997). The present 
study focused on two HR practices, flexible work options and performance evaluation practices, that are under the direct influence of the immediate supervisor and that have been identified in the literature as being especially important to older nurses (see Armstrong-Stassen, 2005; Cohen, 2006; Hatcher et al., 2006; Spetz, 2005). Supervisory behaviours are instrumental to the implementation of performance evaluations and the arrangement of work duties that accommodate the personal needs of employees. Such behaviours provide the opportunity for supervisors to exercise their own judgement and decision-making and create for employees a practical and conceptual link between the organisation and supervisor.

Justice perceptions have an important influence on how employees judge the quality of their exchange relationships with both their supervisor and their organization (Masterson et al., 2000). Two sources of procedural justice have been identified in the literature: organisation-related procedural justice and supervisor-related procedural justice (Blader and Tyler, 2003; Cobb et al., 1997). Organisation-related procedural justice is associated with the formal HR policies and procedures put into effect by the organisation whereas supervisor-related procedural justice is linked to how individual supervisors actually enact these formal policies and procedures (Cobb et al., 1997). In this study, we focused on supervisor-related procedural justice because there is flexibility in the way that individual supervisors may interpret and implement performance evaluations and flexible work arrangements. There is empirical evidence that HR practices influence procedural justice perceptions and that, in turn, perceived procedural justice increases employees' commitment to their organisation (Chang, 2005; Edgar and Geare, 2005; Meyer and Smith, 2000). Given that supervisors play a pivotal role in the 
day-to-day administration of hospital policy, practices and procedures in Canadian hospitals (Laschinger et al., 2008), we predicted that older nurses' assessment of the presence within their hospital of flexible work options and performance evaluation practices targeting older nurses would be significantly positively related to their perceptions of supervisor-related procedural justice.

H1a: Perceived availability of flexible work options targeted to older nurses is expected to be significantly positively related to perceptions of supervisor-related procedural justice.

H1b: Perceived availability of performance evaluation practices supportive of older nurses is expected to be significantly positively related to perceptions of supervisor-related procedural justice.

We proposed that perceptions of supervisor-related procedural justice would be significantly positively related to PSS. That is, older nurses who perceived their immediate supervisor to be administering HR practices fairly would perceive their supervisor to be highly supportive of them. Existing empirical research provides support for this proposed relationship. McFarlin and Sweeney (1992) found that perceived procedural justice was a significant positive predictor of subordinates' evaluation of their supervisor. In a meta-analysis, Cohen-Charash and Spector (2001) reported a weighted mean of $r_{c}=.57$ for perceptions of procedural justice and satisfaction with one's supervisor. Meyer and Smith (2000) found that procedural justice mediated the relationship between HR practices and POS. These researchers concluded that procedural justice is an important factor in shaping employees' perceptions of support, and ultimately their commitment to the organization. We predicted that supervisor- 
related procedural justice would play a similar role in mediating the relationship between the two HR practices and PSS.

H2a: Older nurses' perception of supervisor-related procedural justice is expected to be significantly positively related to PSS.

H2b: Older nurses' perception of supervisor-related procedural justice is expected to mediate the relationship between the HR practices and PSS.

Supervisors serve as agents or representatives of the organisation and employees' perceptions of support from their supervisor are interpreted as indicative of support from the organisation (Eisenberger et al., 1986). Research studies have shown that PSS is a significant positive predictor of POS (Eisenberger et al., 2002). In their meta-analysis, Rhoades and Eisenberger (2002) found a weighted mean of $r_{c}=.64$ for PSS and POS. Therefore, we predicted that older nurses who perceived their immediate supervisor to be highly supportive would also perceive their hospital to be highly supportive whereas older nurses who lacked support from their immediate supervisor would perceive a lack of support from their hospital as well.

There is evidence that the relationship between perceived procedural justice and affective organisational commitment is mediated by POS (e.g., Masterson et al., 2001; Meyer and Smith, 2000). Given that the focus of the present study was on perceived supervisor-related procedural justice instead of organisation-related procedural justice, we posited that PSS would serve as the mechanism mediating the relationship of supervisor-related procedural justice perceptions and POS and, in turn, POS would mediate the relationship between PSS and affective organisational commitment. 
H3a: Older nurses' perception of supervisor support is expected to be significantly positively related to POS.

H3b: Older nurses' perception of supervisor support is expected to mediate the relationship between perceived supervisor-related procedural justice and POS. Drawing on the social exchange perspective and the norm of reciprocity, organisational support theory (Eisenberger et al., 1986) posits that employees develop global beliefs concerning the extent to which their organisation values their contribution and cares about their well-being. Employees interpret such support by the organisation as demonstrating the organisation's commitment to them, creating an obligation to repay the organisation for its commitment and caring. Prior research has found a strong positive relationship between POS and affective organisational commitment (e.g., Meyer and Smith, 2000; Rhoades and Eisenberger, 2002). We predicted that older nurses who perceived their hospital to be supportive would be more committed to their hospital than their counterparts who felt a lack of support from their hospital. In addition, researchers (Hutchison, 1997; Rhoades et al., 2001) have found that POS mediated the relationship between PSS and affective organisational commitment. We therefore proposed that the relationship between PSS and affective commitment would be mediated by POS.

H4a: Older nurses' POS is expected to be significantly positively related to affective organisational commitment.

H4b: Older nurses' POS is expected to mediate the relationship between PSS and affective organisational commitment.

Commitment is a social exchange relationship with POS representing the employer side of the exchange and affective organisational commitment representing the 
employee side of the exchange (Shore et al., 2006). Affective organisational commitment is a key variable in both the POS and turnover literatures (Allen et al., 2003). Affective commitment to the organisation has consistently been found to be significantly negatively related to turnover intention (Meyer, 1997). We therefore predicted that older nurses who felt a strong commitment to their hospital would be significantly more likely to intend to stay with their hospital than their counterparts who were less committed to their hospital. Conceptual models portray, and empirical evidence shows, that organisational commitment mediates the relationship between POS and turnover intention (Allen et al., 2003; Griffeth and Hom, 1995). We therefore predicted that affective organisational commitment would mediate the relationship between POS and intention to remain with one's hospital.

H5a: Affective organisational commitment is expected to be significantly positively related to older nurses' intention to remain with their hospital. H5b: Affective organisational commitment is expected to mediate the relationship between POS and older nurses' intention to remain.

The conceptual model portrays a four-stage mediated model with perceived supervisor-related justice mediating the relationship between the HR practices and PSS, PSS mediating the relationship between perceived supervisor-related procedural justice and PSS, POS mediating the relationship between PSS and affective organisational commitment, and affective organisational commitment mediating the relationship between POS and intention to remain. However, it is possible that the proposed relationships are only partially, and not completely, mediated. Therefore, we also conducted tests of alternative models to determine whether the proposed relationships 
were fully mediated (direct paths remained non-significant) or only partially mediated (direct as well as indirect paths were significant).

\section{METHODOLOGY}

\section{The research context}

This study is part of a larger research programme investigating the implications of the ageing of the Canadian workforce. Given the concerns raised about the ageing of the nursing workforce and an impending nursing shortage in Canada, a series of studies was targeted specifically to older nurses employed in a hospital setting. The nursing shortage is expected to be especially severe in Canada (Canadian Nursing Advisory Committee, 2002). In 2006, the average age of registered nurses in Canada was 45 years with $40 \%$ of RNs aged 50 years or older (Canadian Institute for Health Information, 2007).

\section{Sample and procedure}

To be employed as a nurse in the province of Ontario, nurses must register each year with the College of Nurses of Ontario (CNO). In 2006, a random sample of 2950 registered nurses aged 45 and over employed in a hospital setting was obtained from the CNO registry. Questionnaire packets were mailed to these nurses in 2006 (time 1, T1) and again a year later in 2007 (time 2, T2). There were 1133 completed questionnaires at $\mathrm{T} 1$, giving a response rate of $38 \%$. Of the 2950 questionnaire packets mailed out at $\mathrm{T} 2$, 68 were returned as non-deliverable and 109 nurses indicated they were no longer eligible to participate in the study (no longer employed in a hospital setting, had moved out of the province, or had retired). There were 974 questionnaires received at T2, giving a response rate of 35\%. Twenty-nine questionnaires were incomplete leaving 945 useable questionnaires. To match up the T1 and T2 questionnaires, respondents were 
asked to provide the first four letters of their mother's first name and the last two digits of the respondent's year of birth. It was possible to match up 528 questionnaires.

The average age of the matched sample of nurses at T1 was 52.16 years $(S D=$ 4.32, range 45 to 67). They had been employed in their current hospital an average of 20.62 years $(S D=9.47)$ and as a nurse an average of 28.89 years $(S D=6.18)$. Nearly three-quarters $(72 \%)$ were employed full time. They worked on a variety of work units with the largest percentage being employed in medical-surgery units (15.5\%), obstetricsneonatal units $(12.5 \%)$, intensive coronary care units (10\%), and psychiatric units $(10 \%)$. The respondents were primarily women (98\%), closely reflecting the gender composition of registered nurses in Ontario, and the majority (78\%) was married.

\section{Measures}

Perceptions of the HR practices were assessed at T1 one year prior to the assessment of the other variables in the model. Unless otherwise noted, the response categories ranged from 1 (Strongly disagree) to 5 (Strongly agree). The demographic variables were assessed at both $\mathrm{T} 1$ and $\mathrm{T} 2$.

HR practices. The HR practices were adapted from the flexible work options and performance evaluation scales from Armstrong-Stassen (2005). These HR practices were developed specifically for older nurses. Flexible work options consisted of four items pertaining to flexible work schedules, reduced work week (part time), job sharing, and unpaid leave options. The three performance evaluation items referred to conducting fair performance appraisals free from age bias, providing nurses 45 and over with useful job performance feedback, and providing nurses 45 and over with feedback in a supportive manner. Respondents were asked to indicate the extent to which their hospital 
was currently engaging in each of these HR practices, especially as these relate to nurses 45 and over. The response categories ranged from 1 (Not doing this at all), to 5 (Doing this a great deal).

Perceived procedural justice. Perceived supervisor-related procedural justice was assessed with six items adapted from Colquitt's (2001) Procedural Justice Scale. The lead-in statement informed respondents that the items that followed referred to how the respondent's immediate supervisor handles HR practices relevant to nurses 45 and over such as accommodating requests for flexible work options and providing constructive performance feedback. A sample item is "To what extent have the procedures for implementing these practices been applied consistently by your supervisor?" The response categories ranged from 1 (To a very little extent) to 5 (To a very great extent).

Perceived supervisor support. The 9-item Supervisory Support Scale developed by Greenhaus et al. (1990) was used to measure respondents' perceptions of their supervisor's support. A sample item is “My supervisor makes sure I get the credit when I accomplish something noteworthy on the job."

Perceived organisational support. Perceived organisational support was assessed with four items from the Survey of Perceived Organizational Support scale developed by Eisenberger et al. (1986). The items were selected on the basis of factor loadings reported by Eisenberger et al. and that they reflected valuing employees and caring about their well-being. The referent was changed from organisation to hospital. A sample item is "This hospital really cares about my well-being." 
Organisational commitment. Organisational commitment was measured with three items from the Affective Commitment Scale (Meyer et al., 1993). The referent in the items was changed from organisation to hospital. A sample item is "I feel a strong sense of belonging to this hospital."

Intention to remain. Intention to remain with one's hospital was assessed with five items. Three of the items were adapted from the Intent to Stay measures developed by Mueller et al. (1992), one item was adapted from London and Howat (1978), and one item was developed for the study. A sample item is "I plan to continue working for as long as possible in this hospital."

Demographic variables. The demographic variables included length of time employed as a nurse, length of time employed in current workplace, work status (full time or part time), work unit, age, gender, and marital status.

\section{Data analysis}

Structural equation modelling was conducted to test the hypothesized and alternative models. The analysis was based on the covariance matrix and used maximum likelihood estimation. The overall fit of the model to the data and the significance of the hypothesized paths were assessed with several fit indices including the LISREL goodness-of-fit index (GFI), the adjusted goodness-of-fit index (AGFI), the root-meansquare error of approximation (RMSEA), the non-normed fit index (NNFI), and the comparative fit index (CFI).

\section{RESULTS}

A comparison of the demographic and employment characteristics of nurses who participated at both $\mathrm{T} 1$ and $\mathrm{T} 2$ with those who only participated at T1 showed few 
significant differences. There were no significant differences between the two groups for length of time employed as a nurse $\left(t_{(1118)}=.31, p>.05\right)$, employment status $\left(\chi_{(1)}^{2}=.40\right.$, $p>.05)$, gender $\left(\chi_{(1)}^{2}=.88, p>.05\right)$, marital status $\left(\chi_{(2)}^{2}=1.85, p>.05\right)$, flexible work options $\left(t_{(1100)}=1.38, p>.05\right)$, and performance evaluation $\left(t_{(1090)}=.26, p>.05\right)$. There was a significant difference for age $\left(t_{(1108)}=3.38, p<.01\right)$ and organisational tenure $\left(t_{(1115)}=2.41, p<.05\right)$. Nurses who participated at both times were significantly younger but had been with their hospital significantly longer than those who only participated at T1. A comparison of nurses who participated at both T1 and T2 with those who only participated at $\mathrm{T} 2$ also showed few significant differences between the two groups. There were no significant differences for length of time they had been a nurse $t_{(837)}=1.61, p>$ $.05)$, employment status $\left(\chi^{2}{ }_{(1)}=.21, p>.05\right)$, gender $\left(\chi_{(1)}^{2}=.24, p>.05\right)$, marital status $\left(\chi_{(1)}^{2}=.33, p>.05\right)$, age $\left(t_{(833)}=.13, p>.05\right), \operatorname{PSS}\left(t_{(818)}=1.09, p>.05\right)$, POS $\left(t_{(839)}=\right.$ $.84, p>.05)$, affective organisational commitment $\left(t_{(833)}=.73, p>.05\right)$, and intention to remain $\left(t_{(828)}=.59, p>.05\right)$. There was a significant difference for organisational tenure $\left(t_{(833)}=2.14, p<.05\right)$ and perceived supervisor-related procedural justice $\left(t_{(729)}=2.51, p\right.$ $>$.05) with nurses who participated at both times having significantly greater tenure with their current hospital and perceiving their supervisor to be less fair than those who participated only at T2.

Confirmatory factor analysis was conducted to establish the distinctiveness of the seven multi-item measures (see Table 1). The results showed that the 7-factor model fit the data significantly better than various 6-factor models and a 1-factor model. All of the items in the 7-factor model were significantly related to their respective factor. 
put table one here

\section{Descriptive analysis}

The means, standard deviations, and zero-order correlations are presented in Table 2. Perceptions of the availability of the HR practices were significantly positively associated with perceived supervisor-related procedural justice and PSS, perceived supervisor-related procedural justice was significantly positively related to PSS and POS, PSS was significantly positively related to POS and affective organisational commitment, POS was significantly positively related to affective organisational commitment and intention to remain, and affective organisational commitment was significantly positively related to intention to remain.

put table two here

\section{Overall fit of the hypothesized and alternative models}

The fit indices for the hypothesized fully mediated model and alternative partial mediation models are presented in Table 3. According to the fit indices, the hypothesized fully mediated model demonstrated a good fit to the data. Alternative model 1 demonstrated a good fit to the data as well but only the path between performance evaluation practices and PSS was significant. Alternative model 2 also displayed a good fit to the data and the added direct path between perceived supervisor-related procedural justice and POS was significant. Alternative model 3 displayed an acceptable fit to the data as well and the added direct path between PSS and affective organisational 
commitment was also significant. For alternative model 4, the added direct path between POS and intention to remain was not significant. Based on these analyses, a revised model with direct paths added between perceptions of the performance evaluation practices and PSS, between perceived supervisor-related procedural justice and POS, and between PSS and affective organisational commitment was tested. The revised partial mediation model displayed a significantly better fit to the data compared with the hypothesized fully mediated model $\left(\chi_{\text {diff }}^{2}=30.38, \mathrm{df}_{\text {diff }}=3, p<.001\right)$.

put table three here

\section{Hypothesized relationships}

The maximum likelihood unstandardized and standardized parameter estimates for the revised model are shown in Figure 2. Bolded lines indicate paths added to the original hypothesized model. Perceptions of the availability of flexible work options and performance evaluation practices were significantly positively related to perceived supervisor-related procedural justice, confirming $\mathrm{H} 1 \mathrm{a}$ and $\mathrm{H} 1 \mathrm{~b}$ respectively. Consistent with $\mathrm{H} 2 \mathrm{a}$, perceived supervisor-related procedural justice was significantly positively related to PSS. H2b predicted that perceived supervisor-related procedural justice would mediate the relationship between the HR practices and PSS. Perceived supervisor-related procedural justice fully mediated the relationship between flexible work options and PSS and partially mediated the relationship between performance evaluation options and PSS. PSS was significantly positively related to POS, confirming H3a. H3b predicted that PSS would mediate the relationship between perceived supervisor-related procedural justice 
and POS. Perceived supervisor-related procedural justice had both an indirect effect through PSS on POS as well as a direct effect, indicating partial mediation.

put figure two here

POS was significantly positively related to affective organisational commitment, supporting H4a. H4b predicted that POS would mediate the relationship between PSS and affective organisational commitment. PSS had both an indirect effect on affective organisational commitment through POS as well as a direct effect, indicating partial mediation. Affective organisational commitment was significantly positively related to intention to remain with one's hospital, confirming H5a. H5b predicted that affective organisational commitment would mediate the relationship between POS and intention to remain. The direct path between POS and intention to remain was not significant indicating that affective organisational commitment completely mediated the POS intention to remain relationship.

\section{DISCUSSION}

This study contributes to our existing knowledge by providing insight into possible mechanisms through which perceptions of the availability of HR practices targeting older nurses influence their decision to remain with their hospital. We proposed that perceptions of supervisor-related procedural justice, PSS, POS, and affective organisational commitment are exchange mechanisms that mediate the relationship between flexible work options and performance evaluation HR practices and older nurses' intention to remain with their hospital. Brandes et al. (2004) differentiated between local and global social exchanges. Local social exchanges involve dyadic 
relationships such as the relationship between employee and supervisor. Global social exchanges have to do with the relationship between employee and organization as reflected by POS. The results of the present study suggest that the local social exchange shapes the global social exchange. At the local exchange level, how fairly older nurses perceived their immediate supervisor to be in administering HR practices targeted to nurses 45 and over mediated the relationship between the two HR practices and PSS. In turn, perceived supervisor-related procedural justice was directly related to the global social exchange, POS, as well as indirectly through PSS. Thus, how supportive older nurses perceived their hospital to be was determined by how fair and supportive their immediate supervisor was perceived to be. At the global social exchange level, older nurses reciprocated the perceived support from their hospital by demonstrating a stronger attachment to their hospital through increased commitment and a greater intention to remain. This is consistent with what other studies (Allen et al., 2003; Ng and Sorensen, 2008) have found and shows that older nurses have similar reactions to the global social exchange relationship as do employees of diverse ages in other industry sectors.

The role of the supervisor is well documented in the organisational literature. Gerstner and Day (1997) concluded from their meta-analysis results that the relationship an employee has with his or her supervisor is a lens through which the entire work experience is viewed. The contribution the present study makes to the existing literature is the focus on the relationship between HR practices that are under direct supervisor influence and perceptions of supervisor-related procedural justice. According to Gilliland and Paddock (2005), procedural fairness is HR-function-specific, that is, different HR practices will have different effects on procedural justice depending on 
whether employees view the supervisor or the organisation as responsible for enacting the HR practice. Gilliland and Paddock argued that researchers need to pay attention to which HR practices are being investigated because the outcomes of procedural justice will vary depending on which party (supervisor or organisation) is viewed as responsible for implementing a particular HR practice. To date, much of the research on procedural justice has focused on the organisation and relatively little research attention has been given to the immediate supervisor as a source of perceived procedural justice (Liao and Rupp, 2005). The results of the present study confirm the importance of matching HR practices under the control of the immediate supervisor with supervisor-related procedural justice. Older nurses' perceptions of the availability of flexible work options and performance evaluation practices in their hospital, assessed one year prior to the other variables in the study, were significantly $(p<.001)$ positively related to how fairly they perceived their immediate supervisor was in administering HR practices targeting nurses 45 and over, providing evidence of the link between supervisor-directed HR practices and supervisor-related procedural justice.

Although this study focused on nurse employees' relationships with their supervisor and organisation, our results also have implications regarding the need for the organisation to effectively manage its agency relationship with nursing supervisors. Results indicate that supervisors are perceived by nurses to be key representatives (agents) of the hospital organisation, and supervisory management of relationships with employees will shape employee intentions and attitudes regarding the organisation. According to Eisenhardt (1989), this creates the potential for an agency problem (when the hospital and its supervisors have conflicting goals) as well as the potential for 
differences in risk attitudes that would lead to differences in the willingness of the supervisors to implement HR practices focused on the needs of older nurses. Agency theorists such as Eisenhardt have emphasised the sharing of information and risk-bearing costs as a remedy.

\section{Implications}

The findings of this study provide both scholars and practitioners with important information about the mechanisms through which the perceived presence of HR practices relevant to older nurses operate to foster the retention of older nurses. Overall, few respondents perceived that their hospitals were engaging in HR activities specifically targeted to older nurses. These results are consistent with the findings of other researchers (Armstrong-Stassen, 2005; Spetz, 2005) that hospitals have made little attempt to implement HR strategies that explicitly focus on the needs of older nurses. Our study indicates that some HR practices will help hospitals to retain older nurses, and may provide a competitive advantage as the nursing shortage becomes more severe. Therefore, the first step in any endeavour to promote the retention of older nurses is to convince hospital administrators to implement hospital-wide formal HR policies and practices specifically designed to accommodate the needs and preferences of older nurses and also to ensure that supervisors and older nurses are aware such policies and practices exist. This will send a signal to both supervisors and older nurses that the hospital values its older nurses and at the same time create a supportive organisational culture that is responsive to the needs and preferences of older nurses.

It is important for hospital administrators to recognize the vital role that immediate supervisors play in the process, at least for those HR practices that are directly 
under the supervisors' control. In this study, both HR practices were significant predictors of perceived supervisor-related procedural justice. This signals to hospital administrators that it is not sufficient to develop and post guidelines on how to perform performance appraisals for aging workers, or the types of flexible work arrangements that will be offered by the organisation. Essentially, the hospital has two choices. The first option might be to neutralize the impact of the supervisor by limiting the supervisor's interpretation of the practices. This is a difficult approach to take because it would involve setting fairly inflexible practices, for example, specific performance appraisal questions, timing and scoring as well as setting specific eligibility criteria to qualify for and govern different work arrangements. It is still doubtful, though, whether the individual supervisor's influence can be neutralized completely.

A second option is to develop supervisors into agents of the organisation. This can potentially strengthen the employees' perceptions of unified supervisor and organisational support and increase the likelihood of retention. The findings indicated the importance of supervisors conducting fair and unbiased appraisals of older nurses' job performance, of providing older nurses with useful feedback about their job performance and doing this in a supportive manner. This might entail actively involving supervisors in the development of such policies and practices to ensure that all supervisors understand and 'buy into' these concepts.

HR administrators might also develop additional training for supervisors so that they know how and when to implement the policies and an active follow-up and coaching strategy. Training should also focus on what steps supervisors can take to accommodate the needs and preferences of the older nurses they supervise with the goal of persuading 
these nurses to remain with their hospital. This training would also be aimed at increasing supervisors' awareness of the needs and preferences of older nurses, of the hospital's own need to retain older nurses to address the growing shortage of nurses, and of the importance of conducting performance appraisals free of age bias and providing feedback in a constructive and supportive manner.

The strategic HR literature suggests that HR bundles are superior to individual HR practices because HR bundles have combined synergistic effects that are not found for individual HR practices (Subramony, 2009). In a meta-analysis examining the influence of age on the relationship between the perceived availability of high commitment HR practices and affective organisational commitment, Kooij et al. (in press) distinguished two HR bundles: development and maintenance. The maintenance high commitment HR bundle includes, among other practices, flexible work schemes and performance evaluation practices. In the present study, the CFA results did not support combining these two HR practices into a bundle. Compared with the revised model, the combining of flexible work options and performance evaluation resulted in a poorer fit to the data $\left(\chi_{\text {diff }}^{2}=82.51, p<.001\right)$ as well as a poorer fit compared with the hypothesized and alternative models. One possible explanation for this lack of synergy between the two practices is that they target different types of employee needs. A second possible explanation is the difference in the relationships examined. Kooij et al. examined the relationship between the maintenance high commitment HR bundle and affective organisational commitment whereas we examined the relationship between supervisorcontrolled HR practices and supervisor-related procedural justice. We suggest that future research investigate whether HR bundles exert a stronger influence than individual HR 
practices not only on older nurses' affective commitment but also on the mechanisms that foster commitment, such as perceived supervisor-related procedural justice and PSS or organisation-related procedural justice and POS for those HR practices not under direct supervisor influence.

Researchers should explore the role that other types of perceived supervisorrelated justice, especially interpersonal and informational justice, may play in mediating the relationship between perceptions of HR practices and older nurses' intentions to remain with their hospital. Further research is also needed to investigate other HR practices, such as job redesign, that may be important to the retention of older nurses.

\section{Limitations}

The strengths of the present study were the assessment of perceptions of the presence of the HR practices one year prior to the other measures, the focus on the role of the immediate supervisor as a mechanism through which HR practices operate, and the fact that most of the hypothesized relationships were supported. However, the study also had several limitations. All of the variables except for nurses' perceptions of the extent their hospital was engaging in the HR practices were assessed at the same time and on the same instrument leaving the findings open to the criticism of inflated relationships as a result of common method variance. The confirmatory factor analysis results provided fairly convincing evidence of the distinctiveness of the seven measures but this does not totally rule out problems related to common method variance. Structural equation modelling was used to test the proposed sequence of relationships and for the most part these relationships were confirmed. However, assessing the variables over time would have provided a stronger confirmation of the proposed sequence of relationships as would 
the inclusion of a measure of actually remaining with the hospital even though intentions to stay/leave have been shown to be robust predictors of actual staying or leaving.

\section{Conclusions}

Hospital administrators in Canada and in many other countries are facing a challenge they have never confronted before-an ageing nursing workforce. This is occurring at the same time there is a global shortage of nurses, in large part as a result of the ageing of the nurse population in most developed countries. There is a growing consensus among researchers, professional nursing bodies, and healthcare policy makers that hospital administrators need to take steps to retain their older nurses. One of the proposed strategies to bolster the retention of older nurses is to introduce HR practices that are tailored to their needs and preferences. However, the results of the present study indicate that whereas the presence of such HR practices is definitely a prerequisite, the success of these practices may very well depend on how fairly immediate supervisors administer them. In other words, efforts to retain older nurses will require both supportive HR policies and practices and supportive supervisors. 


\section{REFERENCES}

Allen, D.G., Shore, L.M. and Griffeth, R.W. (2003). 'The role of perceived organizational support and supportive human resource practices in the turnover process'. Journal of Management, 29:1, 99-118.

Armstrong-Stassen, M. (2005). 'Human resource management strategies and the retention of older RNs'. Nursing Leadership, 18:1, 50-66.

Bishop, J.W., Scott, K.D., Goldsby, M.G. and Cropanzano, R. (2005). 'A construct validity study of commitment and perceived support variables: A multifoci approach across different team environments'. Group \& Organization Management, 30:2, 153-180.

Blakeley, J.A. and Ribeiro, V.E.S. (2008). 'Early retirement among registered nurses: contributing factors'. Journal of Nursing Management, 16:1, 29-37.

Blader, S.L. and Tyler, T.R. (2003). 'What constitutes fairness in work settings? A fourcomponent model of procedural justice'. Human Resource Management Review, $13: 1,107-126$.

Blau, P.M. (1964). Exchange and Power in Social Life, New York: Wiley.

Brandes, P., Dharwadkar, R. And Wheatley, K. (2004). ‘Social exchanges within organizations and work outcomes'. Group \& Organization Management, 29:3, 276-301.

Buchan, J. (1999). 'The 'greying' of the United Kingdom nursing workforce: implications for employment policy and practice'. Journal of Advanced Nursing, $30: 4,818-826$. 
Buchan, J. and Calman, L. (2004). The Global Shortage of Registered Nurses: An Overview of Issues and Actions, Geneva: International Council of Nurses.

Canadian Institute for Health Information. (2007). Workforce Trends of Registered Nurses in Canada, 2006, Ottawa: CIHI.

Canadian Nursing Advisory Committee. (2002). Our Health, Our Future: Creating Quality Workplaces for Canadian Nurses, Ottawa: Canadian Nursing Advisory Committee, Advisory Committee on Health Human Resources, Health Canada. Chang, E. (2005). 'Employees' overall perception of HRM effectiveness'. Human Relations, 58:4, 523-544.

Cobb, A.T., Vest, M. and Hills, F. (1997). 'Who delivers justice? Source perceptions of procedural fairness'. Journal of Applied Social Psychology, 27:12, 1021-1040.

Cohen, J.D. (2006). 'The aging nursing workforce: How to retain experienced nurses'. Journal of Healthcare Management, 51:4, 233-244.

Cohen-Charash, Y. and Spector, P.E. (2001). 'The role of justice in organizations: A meta-analysis'. Organizational Behavior and Human Decision Processes, 86:2, 278-321.

Colquitt, J.A. (2001). 'On the dimensionality of organizational justice: A construct validation of a measure'. Journal of Applied Psychology, 86:3, 386-400.

Edgar, F. and Geare, A. (2005). 'HRM practice and employee attitudes: different measures_different results'. Personnel Review, 34:5, 534-549.

Eisenberger, R., Huntington, R., Hutchison, S. and Sowa, D. (1986). 'Perceived organizational support'. Journal of Applied Psychology, 71:3, 500-507. 
Eisenberger, R., Stinglhamber, F., Vandenberghe, C., Sucharski, I.L. and Rhoades, L. (2002). 'Perceived supervisor support: Contributions to perceived organizational support and employee retention'. Journal of Applied Psychology, 87:3, 565-573.

Eisenhardt, K. M. (1989). 'Agency theory: An assessment and review'. Academy of Management Review, 14:1, 57-74.

Gerstner, C.R. and Day, D.V. (1997). 'Meta-analytic review of leader - member exchange theory: Correlates and construct issues'. Journal of Applied Psychology, 82:6, 827-844.

Gilliland, S.W. and Paddock, L. (2005). 'Organizational justice across human resource management decisions' in International Review of Industrial and Organizational Psychology. G.P. Hodgkinson and J.K. Ford (eds), Chichester, England: Wiley \& Sons.

Goodin, H.J. (2003). 'The nursing shortage in the United States of America: an integrative review of the literature'. Journal of Advanced Nursing, 43:4, 335-350.

Gould-Williams, J. and Davies, F. (2005). 'Using social exchange theory to predict the effects of HRM practice on employee outcomes'. Public Management Review, $7: 1,1-24$

Greenhaus, J.H., Parasuraman, S. and Wormley, W.M. (1990). 'Effects of race on organizational experiences, job performance evaluations, and career outcomes'. Academy of Management Journal, 33:1, 64-86.

Griffeth, R.W. and Hom, P.W. (1995). 'The employee turnover process'. Research in Personnel and Human Resources Management, 13, 245-293. 
Hatcher, B.J., Bleich, M.R., Connolly, C., Davis, K., O’Neill Hewlett, P. and Stokely Hill, K. (2006). Wisdom at Work: The Importance of the Older and Experienced Nurses in the Workplace, Princeton, NJ: Robert Wood Johnson Foundation.

Hutchison, S. (1997). 'A path model of perceived organizational support'. Journal of Social Behavior and Personality, 12:1, 159-174.

International Council of Nurses. (2006). The Global Nursing Shortage: Priority Areas for Intervention, Geneva: International Council of Nurses.

Kooij, D.T.W.M., Jansen, P.G.W., Dikkers, J.S.E. and De Lange, A.H. (in press). 'The influence of age on the associations between HR practices and both affective commitment and job satisfaction: A meta-analysis'. Journal of Organizational Behavior.

Laschinger, H.K., Wong, C.A., Ritchie, J., D’Amour, D., Vincent, L., Wilk, P., Armstrong-Stassen, M., Matthews, S., Saxe-Braithwaite, M., Grinspun, D., Shamian, J., McCutcheon, A., Kerr, M., Macdonald-Rencz, S., Oke, B., Denney, D., White, J., and Almost, J. (2008). 'A profile of the structure and impact of nursing management in Canadian hospitals'. Healthcare Quarterly, 11:2, 85-94.

Liao, H. and Rupp, D.E. (2005). 'The impact of justice climate and justice orientation on work outcomes: A cross-level multifoci framework'. Journal of Applied Psychology, 90:2, 242-256.

London, M. and Howat, G. (1978). 'The relationship between employee commitment and conflict resolution behavior'. Journal of Vocational Behavior, 13:1, 1-14. 
Masterson, S.S., Lewis, K., Goldman, B.M. and Taylor, M.S. (2000). 'Integrating justice and social exchange: The differing effects of fair procedures and treatment on work relationships'. Academy of Management Journal, 43:4, 738-748.

McFarlin, D.B. and Sweeney, P.D. (1992). 'Distributive and procedural justice as predictors of satisfaction with personal and organizational outcomes'. Academy of Management Journal, 35:3, 626-637.

Meyer, J.P. (1997). 'Organizational commitment'. International Review of Industrial and Organizational Psychology, 12, 175-228.

Meyer, J.P., Allen, N.J. and Smith, C.A. (1993). 'Commitment to organizations and occupations: Extension and test of a three-component conceptualization'. Journal of Applied Psychology, 78:4, 538-551.

Meyer, J.P. and Smith, C.A. (2000). 'HRM practices and organizational commitment: Test of a mediation model'. Canadian Journal of Administrative Sciences, 17:4, 319-331.

Mueller, C.W., Wallace, J.E. and Price, J.L. (1992). 'Employee commitment: Resolving some issues'. Work and Occupations, 19:3, 211-236.

Ng, T.W.H. and Sorensen, K.L. (2008). 'Toward a further understanding of the relationships between perceptions of support and work attitudes: A metaanalysis’. Group \& Organization Management, 33:3, 243-268.

Rhoades, L. and Eisenberger, R. (2002). 'Perceived organizational support: A review of the literature'. Journal of Applied Psychology, 87:4, 698-714. 
Rhoades, L., Eisenberger, R. and Armeli, S. (2001). 'Affective commitment to the organization: The contribution of perceived organizational support'. Journal of Applied Psychology, 86:5, 825-836.

Rupp, D.E. and Cropanzano, R. (2002). 'The mediating effects of social exchange relationships in predicting workplace outcomes from multifoci organizational justice'. Organizational Behavior and Human Decision Processes, 89:1, 925-946.

Settoon, R.P., Bennett, N. and Liden, R.C. (1996). 'Social exchange in organizations: Perceived organizational support, leader-member exchange, and employee reciprocity'. Journal of Applied Psychology, 81:3, 219-227.

Shore, L.M., Tetrick, L.E., Lynch, P. And Barksdale, K. (2006). 'Social and economic exchange: Construct development and validation'. Journal of Applied Psychology, 36:4, 837-867.

Simoens, S., Villeneuve, M. and Hurst, J. (2005). Tackling Nurse Shortages in OECD Countries, OECD Health Working Papers No. 19, Paris: Organisation for Economic Co-operation and Development.

Spetz, J. (2005). 'The aging of the nurse workforce: Recent trends and future challenges'. Annual Review of Gerontology \& Geriatrics, 25: 65-87.

Subramony, M. (2009). 'A meta-analytic investigation of the relationship between HRM bundles and firm performance'. Human Resource Management, 48:5, 745-768.

Wayne, S.J., Shore, L.M. and Liden, R.C. (1997). 'Perceived organizational support and leader-member exchange: A social exchange perspective'. Academy of Management Journal, 40:1, 82-111. 


\section{TABLE 1}

Confirmatory factor analysis results

\begin{tabular}{|c|c|c|c|c|c|c|c|}
\hline & $X^{2}$ & $\mathrm{df}$ & GFI & AGFI & NNFI & RMSEA & $\begin{array}{c}\mathrm{X}^{2} \\
\text { change }\end{array}$ \\
\hline 7-Factor model & 592.38 & 492 & .92 & .91 & 1.00 & .022 & \\
\hline 6-Factor model ${ }^{\mathrm{a}}$ & 677.39 & 498 & .91 & .90 & .99 & .029 & $85.01 * * *$ \\
\hline 6-Factor model ${ }^{\mathrm{b}}$ & 1468.98 & 498 & .83 & .79 & .97 & .068 & $876.60 * * *$ \\
\hline 6-Factor model ${ }^{\mathrm{c}}$ & 1242.72 & 498 & .85 & .82 & .98 & .060 & $650.34 * * *$ \\
\hline 6-Factor model ${ }^{\mathrm{d}}$ & 928.46 & 498 & .88 & .86 & .99 & .046 & $336.08 * * *$ \\
\hline 6-Factor model ${ }^{\mathrm{e}}$ & 738.20 & 498 & .91 & .89 & .99 & .034 & $145.82 * * *$ \\
\hline 1-Factor model & 4228.94 & 513 & .63 & .57 & .90 & .132 & $3636.56 * * *$ \\
\hline
\end{tabular}

Notes:

${ }^{a}$ Equating flexible work options and performance evaluation practices.

${ }^{\mathrm{b}}$ Equating perceived procedural justice and perceived supervisor support.

${ }^{\mathrm{c}}$ Equating perceived supervisor support and perceived organisational support.

${ }^{\mathrm{d}}$ Equating perceived organisational support and affective organisational commitment.

${ }^{\mathrm{e}}$ Equating affective organisational commitment and intention to remain.

$* * * p<.001$ 
TABLE 2

Means, standard deviations, and correlations for the study variables

\begin{tabular}{llllllllll}
\hline Measures & M & SD & 1 & 2 & 3 & 4 & 5 & 6 & 7
\end{tabular}

\section{Time 1}

1. Work options

2. Performance evaluation
$2.25 \quad 0.73 \quad 0.66$

$\begin{array}{llll}2.32 & 1.09 & 0.39 & 0.92\end{array}$

Time 2

3. Procedural justice

$\begin{array}{lllll}2.00 & 0.90 & 0.25 & 0.30 & 0.93\end{array}$

4. Supervisor support

$\begin{array}{llllll}2.84 & 0.95 & 0.18 & 0.32 & 0.57 & 0.95\end{array}$

5. Organisational support

2.69

6. Organisational commit

$3.29 \quad 0.89$

$\begin{array}{llllll}0.15 & 0.28 & 0.37 & 0.46 & 0.58 & 0.86\end{array}$

7. Intention to remain

$\begin{array}{lllllllll}3.64 & 0.75 & 0.12 & 0.24 & 0.29 & 0.33 & 0.41 & 0.62 & 0.88\end{array}$

Notes:

$N=528$.

Coefficients above 0.08 are significant at $p<0.05$; coefficients above 0.11 are significant at $p<0.01$; coefficients above 0.15 are significant at $p<0.001$ (two-tailed). Scale reliabilities appear in italics on the diagonal. 
TABLE 3

Fit indices for the hypothesized model and alternative models

\begin{tabular}{lcccccccc}
\hline & $\mathrm{X}^{2}$ & $p$ & $\mathrm{df}$ & GFI & AGFI & NNFI & CFI & RMSEA \\
\hline Hypothesized model $^{\mathrm{a}}$ & 637.86 & $<.001$ & 506 & .92 & .90 & .99 & .99 & .025 \\
Alternative model 1 $^{\mathrm{b}}$ & 626.20 & $<.001$ & 504 & .92 & .90 & .99 & 1.00 & .024 \\
Alternative model 2 $^{\mathrm{c}}$ & 629.77 & $<.001$ & 505 & .92 & .90 & .99 & 1.00 & .024 \\
Alternative model 3 $^{\mathrm{d}}$ & 627.64 & $<.001$ & 505 & .92 & .90 & .99 & 1.00 & .024 \\
Alternative model 4 $^{\mathrm{e}}$ & 637.52 & $<.001$ & 505 & .92 & .90 & .99 & .99 & .025 \\
Revised model $^{\mathrm{f}}$ & 607.48 & $<.01$ & 503 & .92 & .91 & 1.00 & 1.00 & .022 \\
\hline
\end{tabular}

Notes:

${ }^{\text {a }}$ Complete mediation model.

${ }^{\mathrm{b}}$ Partial mediation model with direct paths added between the HR practices and perceived supervisor support.

${ }^{\mathrm{c}}$ Partial mediation model with direct paths added between perceived supervisor-related procedural justice and perceived organisational support.

${ }^{\mathrm{d}}$ Partial mediation model with a direct path added between perceived supervisor support and affective organisational commitment

${ }^{\mathrm{e}}$ Partial mediation model with a direct path added between perceived organisational support and intention to remain.

${ }^{\mathrm{f}}$ Hypothesized model with added paths between perceptions of the performance evaluation practices and perceived supervisor support, between perceived supervisorrelated procedural justice and perceived organisational support, and between perceived supervisor support and organisational commitment. 
FIGURE 1

Conceptual model

Supervisor

Administered

HR Practices

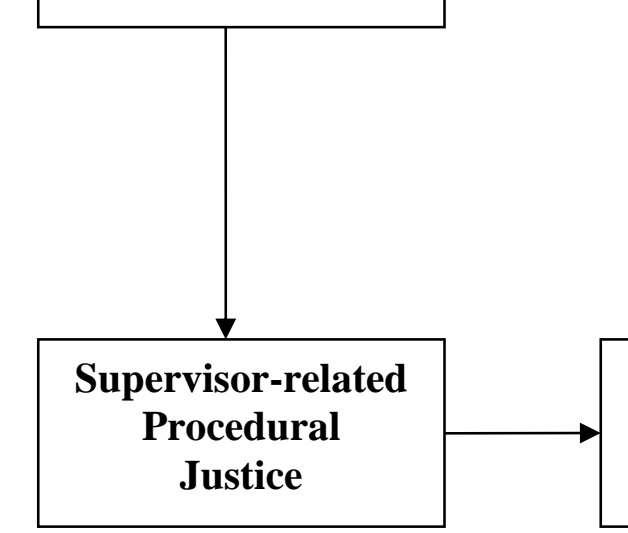

Perceived

Supervisor Support
Perceived Organizational Support
Affective Organisational Commitment

Intention to

Remain with Hospital 


\section{FIGURE 2}

Parameter estimates for the revised model

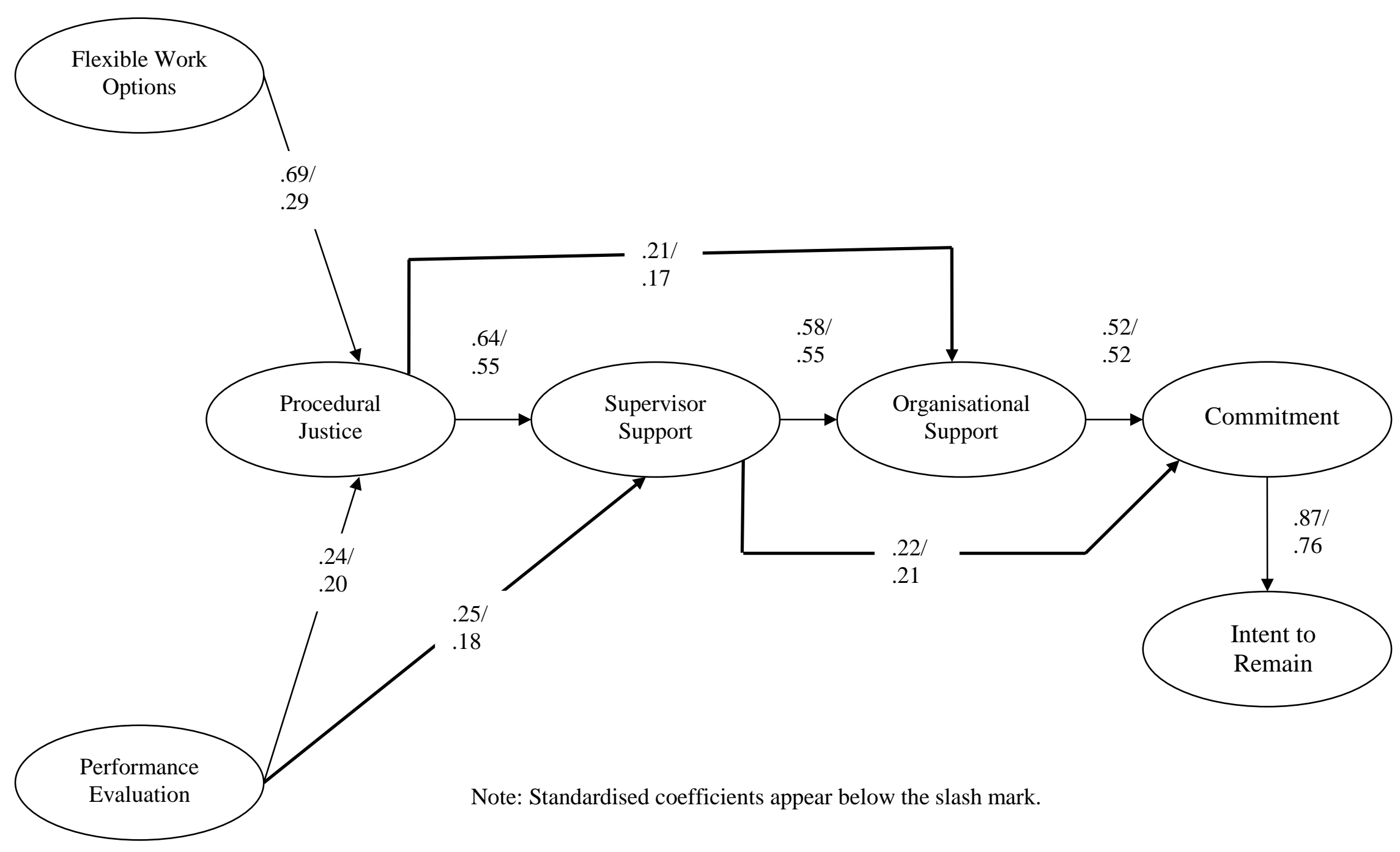

